\title{
A sociologia da saúde no Brasil - a construção de uma identidade
}

\author{
The sociology of health in Brazil - the creation of an identity
}

Everardo Duarte Nunes ${ }^{1}$

\footnotetext{
${ }^{1}$ Departamento de Saúde Coletiva, Faculdade de Ciências Médicas, Universidade Estadual de Campinas. Cidade Universitária, Barão Gerado. 13.081-970 Campinas SP Brasil. evernunes@uol.com.br
}

\begin{abstract}
This article analyzes the historical, social and cognitive dimensions of the sociology of medicine in the construction of its identity, from Wolf Lepenies' perspective. It is understood that the construction of an identity does not end with the first historical manifestations, but is consolidated when it is institutionalized and structured as a field of knowledge by creating its own forms of cognitive expression. The text is divided into three parts: in the first the precursors are presented, highlighting the role played by some travelers, naturalists and folklore scholars, followed by "social physicians-scientists" and the first social scientists (1940-1969). In the second part, aspects of the consolidation of the social sciences in health are presented at two significant moments, namely the 1970s and 1980s. In the third part, the issues raised by the field are addressed in general terms. It is considered that once the main structural stages are in place there is still a need for the formation of new generations of social scientists in health. It is also essential to disseminate scientific production and to ensure that the relations are studied in depth and institutionalized with the sociological matrices on the one hand and with the field of health on the other.
\end{abstract}

Key words The sociology of health, Historical identity, Social identity, Cognitive identity
Resumo O artigo analisa na perspectiva de Wolf Lepenies as três dimensões - histórica, social e cognitiva - o campo da sociologia da saúde na construção de sua identidade. Entende-se que a construção de uma identidade não se encerra com as primeiras manifestações históricas, mas se consolida quando se institucionaliza e progressivamente se estrutura como campo do conhecimento criando suas formas próprias de expressão cognitiva. O texto está dividido em três partes: na primeira, são apresentados os precursores, destacando o papel desempenhado por alguns viajantes, naturalistas e estudiosos do folclore, seguidos pelos "médicos-cientistas sociais" e pelos primeiros cientistas sociais (1940-1969); na segunda, aspectos da consolidação das ciências sociais em saúde - dois momentos: os anos 70 e os anos 80; na terceira parte, de forma geral, são abordados os temas tratados pelo campo. Considera-se que, completadas as principais fases de sua disciplinarização há ainda a necessidade de que se estruturem os canais para a formação das novas gerações de cientistas sociais em saúde, se desenvolvam meios de divulgação da produção científica e se aprofundem e se institucionalizem as relações, de um lado, com as matrizes sociológicas e de outro com o campo da saúde.

Palavras-chave Sociologia da saúde, Identidade histórica, Identidade social, Identidade cognitiva 


\section{Introdução}

Muitos trabalhos, ao longo dos últimos anos, procuraram desvendar a trajetória dos estudos sociológicos em saúde no Brasil e dentro do material empírico utilizado e das formulações teóricas que os embasam tornaram-se a fonte de informações para os estudiosos da sociologia da ciência, da história do pensamento social em saúde e da sociologia da saúde.

Neste artigo, analisamos o processo de construção da sociologia da saúde tomando como referência a perspectiva do sociólogo alemão Wolf Lepenies de analisar um campo do conhecimento a partir de três dimensões que lhe conferem identidade: a histórica, a social e a cognitiva ${ }^{1}$.

Entendemos que a construção de uma identidade não se encerra com as primeiras manifestações históricas, mas se consolida quando se institucionaliza e progressivamente se estrutura como campo do conhecimento, criando suas formas próprias de expressão cognitiva. Apresentamos o texto em três partes: na primeira, os precursores, destacando o papel desempenhado por alguns viajantes, naturalistas e estudiosos do folclore, seguidos pelos "médicos-cientistas sociais" e pelos primeiros cientistas sociais (1940-1969); na segunda, aspectos da consolidação das ciências sociais em saúde - dois momentos: os anos 70 e os anos 80; na terceira parte, de forma geral, são abordados os temas tratados pelo campo.

\section{Identidade histórica}

Quando analisamos as origens das ciências sociais em saúde no Brasil, constatamos, que, embora esse campo tenha se firmado a partir de datas muito recentes (segunda metade dos anos 60 do século XX), apresenta um passado rico em ensaios, pesquisas, propostas para o ensino e projetos de intervenção, notadamente, por meio das atividades em educação sanitária. São ensaios sobre a medicina, a saúde, os remédios, os hospitais, as chamadas "doenças tropicais" com incursões em várias disciplinas, como a sociologia, a antropologia, a educação, a história, a geografia e o folclore. Esta revisão não pretende esgotar todos os nossos "antecedentes", mas apontar o que estamos considerando como precursores e pioneiros. Novaes ${ }^{2}$ ao traçar a trajetória do pensamento social em saúde, recupera a noção utilizada por Antônio Cândido ${ }^{3}$ quando se refere a "manifestações" "manifestações literárias" para distingui-las dos "sistemas literários" - articulação entre autor, obra e público - na formação da literatura brasileira). Retomamos essa noção que nos parece adequada para caracterizar os momentos iniciais de um campo de conhecimento que ainda não era sistematizado e cuja institucionalização ocorreria muitas décadas mais tarde.

\section{Os precursores}

\section{Os viajantes}

Laurentino Gomes ${ }^{4}$ cita que em 1949, o historiador e pioneiro da biblioteconomia no Brasil, Rubens Borba de Morais, catalogou um total de 266 viajantes classificados em cinco grupos: comerciantes, mineradores e outros homens de negócio; nobres, diplomatas, militares e funcionários de governo; cientistas; pintores e paisagistas; aventureiros, curiosos e gente que chegou ao país quase por acaso.

Entre os viajantes que se voltaram para as questões das doenças o principal nome é de José Francisco Xavier Sigaud [1796-1856]. Segundo Ferreira ${ }^{5}$, o livro desse médico e naturalista francês, naturalizado brasileiro, médico da família imperial brasileira, $D u$ climat et des maladies $d u$ Brésil (1844), "Escrito sob a influência do neohipocratismo, exigiu de Sigaud vasto conhecimento da história natural, cultural e social das províncias do Império do Brasil. Seu pressuposto teórico era que existia forte correlação entre os fenômenos patológicos, o ambiente natural e o padrão sociocultural vigente". Nele o viajante trata da climatologia, da geografia médica, da patologia intertropical e da estatística médica do Brasil, revelando "o talento de Sigaud como higienista e historiador da saúde". Segundo Ferreira ${ }^{5}$, o autor inaugura "a tradição de investigação científica dedicada ao tema das "doenças nacionais", que sobreviveria ao esgotamento do modelo higienista clássico". Em outro trabalho, Ferreira ${ }^{6}$ irá destacar a importância desse livro no pensamento de Gilberto Freyre para a compreensão da sociedade brasileira, sendo um dos autores mais citados em Casa Grande e Senzala quanto trata da questão relacionada à insalubridade do clima tropical como obstáculo ao projeto colonizador português.

Outro destaque é o médico francês Alphonse Rendu, que entre 1844 e 1845, foi encarregado pelo ministério da Instrução Pública da França de inventariar as doenças que mais acometiam os habitantes locais e os europeus que vinham se fixar no Brasil. Edler ${ }^{7}$ salienta que esse trabalho "permitirá destacar uma fase característica daquele ramo da medicina acadêmica europeia, a geografia médica, que institucionalizou a viagem 
exploratória como condição inerente à produção do conhecimento médico e à formação profissional do médico cujo tirocínio fosse voltado para as populações residentes nos trópicos".

Entretanto, antes desses médicos, outros viajantes também deixaram informações sobre as enfermidades de diversas regiões do Brasil no século XIX. É o caso dos naturalistas Johann Baptiste von Spix [1781-1826] e Karl Friedrich von Martius [1794-1868]. Ambos formaram-se em medicina; Spix dedicou-se à zoologia e von Martius à botânica. Em circunstanciado trabalho Lisboa ${ }^{8}$ conta-nos sobre a viagem e o relato que fizeram ao percorrerem o Brasil de 1817 a 1820 , procurando "perfilar a visão de natureza dos autores" e "identificar as bases do 'projeto civilizatório" desses viajantes.

\section{Os folcloristas}

O historiador da medicina Santos Filho ${ }^{9}$ relata que até o século XIX a prática médica no Brasil, pela precariedade da formação em medicina, esteve a cargo, de forma preponderante, da medicina popular. Novaes ${ }^{2}$ escreve que não se pode "negligenciar a importância das medicinas dos índios do Brasil, das medicinas religiosas nem das crenças e práticas terapêuticas populares”, pois constituem parte dessa configuração pluralista da medicina brasileira, sendo que "No Brasil, por longo tempo, a etnomedicina dominou largamente a produção na área da antropologia médica".

Ressalte-se que a partir dos anos 50 são publicados alguns dos textos mais expressivos dos estudos folclóricos em saúde, como os de $\mathrm{Ca}$ bral $^{10}$ e Araújo ${ }^{11}$. Segundo Carvalho ${ }^{12}$, é o período marcado pelas ideias de moderno e de progresso, no sentido de superação de etapas - "com a modernização da agricultura e sua adequação às exigências do progresso, dando lugar à industrialização, símbolo máximo da modernização daqueles tempos". Ao mesmo tempo, foi nessa década que ocorreu o "movimento folclórico", iniciado em 1947, estende-se e atravessa a década de 1950 visando o reconhecimento do folclore como saber científico. Nesse período é realizado o Primeiro Congresso do Movimento Folclórico do Brasil (1951) que não somente definiu fato folclórico - "maneiras de pensar, sentir e agir de um povo, preservadas pela tradição popular e pela imitação" -, mas reconheceu o seu estudo como integrante das ciências antropológicas e culturais ${ }^{12}$.

Lembramos que em suas relações com a medicina e a doença existem várias denominações para se contraporem à chamada "medicina eru- dita", como: "medicina rústica", "medicina popular", "medicina mágica", "medicina religiosa" e outras. Para Araujo ${ }^{11}$, a medicina rústica é o "conjunto de técnicas, de fórmulas, de remédios, de práticas, de gestos de que o morador da região estudada lança mão para o restabelecimento da saúde ou prevenção de doenças”.

Queiroz e Canesqui ${ }^{13}$ criticam que "De um modo geral, a maioria dos autores "folcloristas", quando apresentam uma preocupação teórica ou uma elaboração mais complexa do tema, como ocorre, por exemplo, com Cabral e Araújo, consideram a "medicina popular" como um conjunto de crenças e práticas "rústicas" e "imitativas", resultado da difusão de medicinas eruditas passadas e das diferentes etnias que compuseram a população brasileira”. Ressaltam que dois trabalhos iriam marcar diferença quando comparados a esses, os de Fernandes ${ }^{14}$ com pesquisas sobre folclore realizadas em 1942 e Fontenelle ${ }^{15}$.

Witter ${ }^{16}$ salienta que foram os antropólogos e os sociólogos os primeiros a se dedicarem aos estudos sobre as "práticas de cura entre os populares", e mais tarde (década de 1990) os historiadores. Para ela os trabalhos de Loyola ${ }^{17}$, Montero ${ }^{18}$, Oliveira ${ }^{19}$, "fugiram das abordagens folclóricas e religiosas acerca das práticas de cura populares e encontraram nelas e em seus praticantes uma coerência nas ideias relativas ao funcionamento do corpo e às ações do mundo e dos homens sobre ele". Acrescenta que, "a diferença de entendimento advinha de uma racionalidade específica e de necessidades práticas e simbólicas diferentes, mas não destituídas de valor, nem atrasadas ou fruto simplesmente da ignorância e da superstição. Pelo contrário, as práticas de cura populares seriam uma criação original e não simplesmente reativa a outros saberes ou à falta deles".

Na pesquisa sobre as ciências sociais em saúde na América Latina, período de 1950-1985, a categoria "medicina tradicional" englobava 18,4\% da produção; de 1950-1979, totalizava 26,8\% e decrescia para 5,6\%, de 1980-1985 ${ }^{20}$.

Para Vilhena $^{21}$ (apud Novaes ${ }^{2}$ ), “o movimento folclórico se viu derrotado ao longo do processo de consolidação do campo intelectual brasileiro e, no entanto, durante a década de 50 mostrou vigor e capacidade para responder aos dilemas intelectuais e institucionais que afligiam os nossos intelectuais. Contudo, seus membros foram reconhecidos menos por esse papel e mais pelos esforços de alguns deles em compor obras e trajetórias influentes em antropologia e sociologia”. 


\section{Os médicos cientistas-sociais}

Geralmente, na referência aos médicos-cientistas sociais, o primeiro nome que se destaca é o de Nina Rodrigues [1862-1906]. Paiva ${ }^{22}$ chama a atenção para a importância que teve o estudo de Mariza Correa ${ }^{23}$ sobre esse médico e antropólogo que dá nome à escola formada por Arthur Ramos [1903-1949] e Afrânio Peixoto [18761947], mas como observou Corrêa, há distanciamentos entre os projetos de cada geração de pesquisadores.

Esses médicos voltaram-se para a antropologia, num momento em que não existia uma formação especializada nesse campo, associando-a à psiquiatria, à medicina forense, aos estudos sobre raça e eugenia.

Para Novaes2, "Nina Rodrigues tipifica o intelectual aderido a uma das formas que o pensamento social em saúde teve no Brasil: o pensamento higienista". Autor de uma diversidade bastante grande de pesquisas - das questões do saneamento sanitário à questão racial, dentro dos enfoques das teorias eugênicas então vigentes -, Nina Rodrigues defendia um estado centralizador e uma visão unicausal da doença e era adepto da teoria dos miasmas para explicar a propagação das doenças. Cumpre destacar, como faz $\mathrm{Maio}^{24}$, que Participante ativo do processo de institucionalização da medicina na virada do século, Nina canalizou suas ações para uma série de investimentos que resultaram no avanço da autonomia da categoria médica. Para isso, competiu com a tradição clínica, até então dominante, demarcando o espaço de atuação específica da medicina legal.

\section{Dos anos 40 à década de 60}

Nesta tentativa de traçarmos alguns aspectos da trajetória histórica da sociologia da saúde, um período especialmente instigante e recentemente revisitado pelos historiadores da saúde, sociólogos da saúde, educadores e antropólogos é aquele que se estende do final dos anos 30 até meados dos anos 60 do século XX. Nessa época destacam-se os cientistas sociais estrangeiros que aqui chegaram logo após a criação da Escola Livre de Sociologia e Política de São Paulo - ELSP (1933), atual Fundação Escola de Sociologia e Política de São Paulo (FESPSP) e, da Faculdade de Filosofia, Ciências e Letras - FFCL, da USP (1934), atual Faculdade de Filosofia, Letras e Ciências Humanas (FFLCH - USP). Acrescente-se a criação do SESP (Serviço Especial de Saúde Pública), em 1942, que teria papel importante no campo da saúde e das atividades de antropólogos e sociólogos.
Entre os que vieram para a recém-criada FFCL, destacamos Roger Bastide [1898-1974]. Chegou em 1938, permaneceu no Brasil durante dezesseis anos e formou as primeiras gerações de sociólogos brasileiros (Florestan Fernandes, Maria Isaura Pereira de Queiroz, Gilda de Mello e Souza, Fernando Henrique Cardoso e muitos outros). Realizou marcantes trabalhos no campo da sociologia e da antropologia, incluindo os estudos de psiquiatria social, psicanálise e doença mental, relações raciais, folclore. Embora precedida por vários trabalhos ${ }^{25,26}$, a sua principal obra no campo da sociologia da doença será publicada em 1965, tratando da doença mental ${ }^{27}$.

Para a ELSP, chegou em 1939 o antropólogo norte-americano Donald Pierson [1900-1995] formado pela Escola Sociológica de Chicago e que teve forte influência sobre a primeira geração de pós-graduandos em sociologia e antropologia no Brasil. Entre seus orientandos citamos Oracy Nogueira [1917-1996] com seu estudo sobre pacientes tuberculosos internados ${ }^{28}$. Entre os orientandos de outro antropólogo da ELSP, Herbert Baldus [1899-1970], que chegou ao Brasil em 1923, voltou para a Alemanha (1928), para estudar etnologia e, em 1933, transferiu-se definitivamente para o Brasil, assumindo em 1939 a cadeira de Etnologia Brasileira da ELSP, citamos Gioconda Mussolini [1913-1969], com a pesquisa sobre a doença e morte em duas tribos brasileiras ${ }^{29}$. Outro ex-aluno da ELSP, Alceu Maynard de Araújo ${ }^{11}$, após a conclusão do bacharelado em 1944, participou de pesquisas de comunidade no Projeto de Pesquisas no Vale do São Francisco (1950), orientadas por Pierson, publicou em 1959, Medicina rústica, com parte do material pesquisado, como é detalhadamente descrito por Oliveira ${ }^{30}$.

Data, também, dos anos 40, o trabalho de outro egresso da pós-graduação da ELSP e que se tornaria referência maior da sociologia brasileira - Florestan Fernandes. Sua dissertação de mestrado, de 1947, orientada por Herbert Baldus, versou sobre a organização social dos Tupinambá, e nesse mesmo ano da defesa ele publicou dez artigos sobre a "Viagem ao Tocantins" do médico Júlio Paternostro que ele denominou "Um retrato do Brasil". Fernandes ${ }^{31}$ "se apoiou naquela fonte para discutir o significado da oposição entre litoral e sertão e indicar a necessidade de pesquisas feitas por especialistas sobre as populações e as relações sociais no interior do país. Ressaltou ser o trabalho de Paternostro um trabalho "interessado", motivado pelas convicções socialistas do médico, o que conferia um caráter 
de denúncia ao livro, que via como aspecto positivo, a despeito de apontar simplificações, omissões e superficialidade no tratamento de algumas questões", como analisam Maio e Lima ${ }^{32}$. Fernandes $^{31}$, no que se refere à saúde, aponta a presença e importância da medicina popular e suas relações com a medicina científica, incluindo a utilização de curandeiros, defendida por Paternostro, após algum treinamento com os médicos.

Essas manifestações fazem parte do momento inaugural das ciências sociais em São Paulo, como atividade acadêmica e que se completa com os cientistas sociais que participaram dos projetos em saúde pública. Essa vertente inicia as atividades nos anos 40 , estendendo-se por toda a década de 50, também teve a participação estrangeira, relacionou-se diretamente com o projeto de educação sanitária, desenvolvido pelo SESP.

Estudos recentes ${ }^{32-37}$ têm resgatado a contribuição trazida por muitos cientistas sociais que participaram desse movimento no campo da saúde pública, destacando-se Jose Arthur Rios [1921]. Seus artigos "Ciências sociais e saúde pública" e "A saúde como valor social" foram publicados em $1953^{38,39}$. Foi coordenador da seção de Pesquisa Social do SESP (criada em 1953) da qual fariam parte dois outros cientistas sociais, Luiz Fernando Raposo Fontenelle [1929-2008] autor de "Aimorés: análise antropológica de um programa de saúde" 15 e Carlos Alberto de Medina [1932-2010] que também se dedicaria aos estudos urbanos, favelas, família ${ }^{40}$.

Como escreve $\mathrm{Cardoso}^{37}$, esses cientistas exerceram forte influência no campo dos estudos conhecidos como "estudos de comunidades" e "conduzidos de modo a implantar no país um modelo de saúde preventiva baseado na perspectiva de organização das comunidades assistidas". A educação sanitária seria parte integrante dessa corrente de pensamento, preocupada em "formar a consciência sanitária como um dos objetivos prioritários para o sucesso de sua intervenção".

Nesse processo, dois antropólogos norteamericanos serão personagens importantes: Charles Wagley [1913-1991] e Kalervo Oberg [1901-1973].

Lembre-se que, inicialmente, a educação para a saúde não se apresenta como prática sanitária, mas como programa para formação e aperfeiçoamento de profissionais que ingressam no SESP e somente em 1944 é que se estabelece a Divisão de Educação Sanitária - DES. Nessa data, Charles Wagley, que já havia estado na Amazô- nia, assume a direção da DES, "define as primeiras diretrizes para um programa de educação sanitária dirigido aos escolares, aos setores populares das áreas rurais e das periferias urbanas e ao treinamento de pessoal" ${ }^{34}$. Em "A educação sanitária no Brasil" Wagley ${ }^{41}$ irá desenvolver suas ideias sobre a educação sanitária, relacionandoa com o problema da alimentação, na modificação de hábitos e atitudes relativos à saúde, ao papel do médico que deveria "determinar o que deve ser ensinado ao povo", pois "a classe médica é o grupo melhor preparado cientificamente no Brasil". Propõe a utilização dos recursos audiovisuais devido à elevada proporção de analfabetos no Brasil (Censo de 1940), com projetores de filmes e slides, aparelhos de som, máquinas fotográficas importados dos Estados Unidos. Observe-se que os filmes abordando temas da saúde têm forte componente ideológico, visando difundir valores a serem incorporados pelas camadas populares. $\mathrm{O}$ alto custo dos filmes e as dificuldades de seu uso conduziram à busca de outros meios mais adequados às características das camadas populares das áreas rurais e periféricas. Na história do SESP irá ocorrer a sua integração com outras instituições, como a articulação com a Campanha de Educação de Adolescentes e Adultos, em 1947, e, em 1948, na avaliação realizada pelos sanitaristas do Serviço será apontada a necessidade de incluir a assistência médica curativa e as medidas preventivas. Nos anos 50, ocorrerão grandes mudanças no SESP convênios com os estados, novas propostas de educação para a saúde e a incorporação das novas ideias sobre o desenvolvimento econômico (modelo de Rostow), incluindo a proposta de realização de estudos de comunidades ${ }^{34}$. O modelo adotado pelo SESP será alvo de críticas, inclusive pelos sanitaristas do Serviço que fazem, em 1956, uma autocrítica (citada por Braga e Paula $^{42}$ ) ressaltando a tentativa de aplicar em nosso país esquemas utilizados em outros países, sem considerar as diferenças econômicas, sociais e tecnológicas.

Ainda na década 1940-1950 há destaques importantes para o conhecimento da saúde no Brasil. Citamos Josué de Castro [1908-1973] médico, geógrafo, cientista social, Gilberto Freyre [1900-1987] sociólogo, antropólogo, historiador e o sociólogo Alberto Guerreiro Ramos [19151982]. O primeiro, pelos estudos em nutrição e alimentação, desde os anos 30, e a publicação de Geografia da fome, em 1946 $6^{43}$; o segundo, que após ministrar um curso de sociologia médica, no Recife em 1965, publicaria, em 1967, Sociolo- 
gia da medicina ${ }^{44}$ e Guerreiro Ramos, que na década de 1950 procurou "articular problemas sociais como a mortalidade infantil a uma perspectiva de desenvolvimento nacional segundo a qual a industrialização e o crescimento econômico alavancados pelo Estado constituíam as principais vias de transformação das condições sanitárias do país"45.

O período que estamos analisando em relação às ciências sociais em saúde foi pesquisado por Villas Bôas que se dedicou à produção brasileira das ciências sociais, lato senso, dos anos de 1945-1964, onde podem ser distinguidas duas categorias de estudos - "científicos" e "ideológi$\cos$ " 46 . Como interpreta a autora, "Produzir conhecimento naquele contexto histórico, certamente significava contribuir para o processo de transformações e consumação de um projeto histórico" ${ }^{47}$. Estas observações não são estranhas às ciências sociais em saúde desse período, como visto nos parágrafos anteriores, quando alguns projetos almejavam contribuir para um processo de mudanças.

O crescente interesse pelas ciências sociais a partir da metade dos anos 60 e início dos 70 estará associado a um projeto de mudança de caráter institucional - o ensino médico. Como resultado de discussões que ocorreram desde a segunda metade dos anos 50, acentuam-se as críticas aos modelos que estruturavam a educação médica na América Latina e que em outros países já haviam produzido tentativas de reformas do ensino, dirigidos à atenção integral aos pacientes, assim como à integração dos conhecimentos biológicos, psicológicos e sociais na compreensão do processo da doença. Além das questões educacionais contatava-se a presença de preocupantes indicadores de saúde mostrando a alta mortalidade infantil e o desamparo oficial de extensas camadas da população sem atenção médica básica. Os caminhos encontrados: incrementar estudos que dessem conta dos aspectos sociais e coletivos da saúde, formar pessoal especializado quer seja na especialização em saúde pública, quer seja nos cursos de pós-graduação e formalizar apoios financeiros para as pesquisas em saúde.

\section{Identidade social}

Para se entender o momento em que a sociologia da saúde inicia o estabelecimento de sua identidade social, fazemos inicialmente uma referência à sociologia e à saúde coletiva no Brasil. Entendendo-se que a identidade social “é forjada pelo processo de institucionalização através do qual a disciplina procura se estabilizar do ponto de vista de sua organização" ${ }^{47}$, a sociologia inicia este processo com a criação dos primeiros cursos de sociologia (ELSP, 1933, USP, 1944, Universidade do Distrito Federal/RJ, criada em 1935 e extinta em 1939), e a saúde coletiva com a criação de uma associação que estatuiu os seus objetivos de ensino, pesquisa e extensão, em 1979, criando a Abrasco (Associação de Pós-Graduação em Saúde Coletiva) e, quase vinte anos depois, iniciando a publicação da sua revista - Ciência e Saúde Coletiva, em 1996.

Podemos dizer que as ciências sociais, de forma geral, passam a fazer parte da academia no momento em que o seu ensino é introduzido de forma sistematizada nas escolas médicas, na metade dos anos 60, posteriormente na enfermagem e, na pós-graduação, nos anos 70. Ao mesmo tempo é a partir dos anos 70 que cientistas sociais defendem suas teses de doutorado com temáticas da saúde, em diversas instituições universitárias brasileiras como UNICAMP, USP, UERJ, UFMG, dentre outras. Tendo conseguido efetivar o seu projeto no campo pedagógico, a sociologia da saúde, no final dos anos 70 e nos anos 80, estende suas atividades para a esfera das políticas de saúde, num momento em que as propostas de reforma sanitária brasileira tornam-se ponto de referência de médicos, cientistas, políticos, educadores, como parte do processo de redemocratização da política nacional. Muitos dos sociólogos que participaram desse movimento são os mesmos que haviam participado da introdução do ensino na área da saúde e continuaram nas décadas de 80 e 90 junto ao movimento de formalização da Saúde Coletiva. Sem dúvida, neste campo os cientistas sociais têm sido protagonistas de vanguarda e a colaboração trazida, que se iniciara nos cursos de graduação, volta-se novamente para a graduação da saúde coletiva, na formação de sanitaristas, que até então acontecia somente em cursos de pós-graduação e especialização.

Sem dúvida, o magistério foi a porta de entrada do cientista social no campo da saúde, e segundo pesquisa recente a partir de informações da Plataforma Lattes foram encontrados 238 cientistas sociais com atividades no campo da saúde ${ }^{48}$, em sua maioria como professores e pesquisadores.

A diversificação de atividades é constatada por Barros ${ }^{49}$ no estudo sobre a inserção dos cientistas sociais na gestão dos serviços de saúde. Nessa pesquisa foram identificados 31 profissi- 
onais e 14 pesquisados em profundidade nos 645 municípios do Estado de São Paulo (70,7\% responderam à consulta telefônica) e que exerciam atividades junto às Secretaria Estadual e Municipais de Saúde. O autor trabalha com as ideias de credencial, conhecimento e contradição construindo uma tipologia que tem como tipo ideal a presença de forte credencial com muito conhecimento, mas existente somente no plano ideal. A célula que apresenta fraca credencial e pouco conhecimento seria exemplificada pelos cientistas sociais que estão na rede de serviços de saúde.

Outra forma de comprovação que assegura que a sociologia da saúde encaminha-se para formalizar a construção da sua identidade social pode ser vista na constituição de grupos de pesquisa, seminários e congressos. Pesquisa sobre os grupos de pesquisa em saúde no Brasil constatou a existência de 42 grupos específicos de sociologia da saúde no campo da saúde coletiva que totaliza 653 grupos. Pode parecer um número pequeno $(1,87 \%)$, mas deve-se levar em consideração que muitos dos outros 47 campos disciplinares da saúde coletiva também utilizam métodos e teorias das ciências sociais ${ }^{50}$.

A visibilidade do campo pode, ainda, ser constatada pela realização de atividades coletivas. A área já realizou seis congressos nacionais, tendo o sexto ocorrido em novembro de 2013, no Rio de Janeiro. Foram também realizados dois seminários em Campinas (2011 e 2012) e um Congresso Latino-Americano de Ciências Sociais em Saúde (2004). Acrescente-se que a Sociedade Brasileira de Sociologia (SBS) incorporou entre os grupos de trabalho o de Saúde e Sociedade e a Associação Nacional de Pós-Graduação em Ciências Sociais (ANPOCS) incluiu entre os seus seminários temáticos a questão da saúde e políticas públicas.

A produção científica desses congressos vem sendo analisada fornecendo importantes aportes para a área. O trabalho de Gomes e Goldemberg $^{51}$ revisa os encontros e os congressos de Ciências Sociais em Saúde (1993, 1995 e 1999) apontando um crescente desenvolvimento de temáticas e enfoques nos campos da antropologia, sociologia e epidemiologia. Dos achados do trabalho destacamos no âmbito da antropologia, não somente uma "permanência do passado nas temáticas voltadas para as práticas tradicionais", vistas em momentos anteriores, mas a preocupação com "as racionalidades embutidas nessas práticas e nas relativas à medicina oficial" - antes denominadas sistemas tradicionais, agora chamadas de práticas alternativas; no âmbito da sociologia, fazem-se presentes temas relacionados a: descentralização, conselhos, participação, cidadania e movimentos sociais, saúde da família; em relação à epidemiologia, mais de 1/3 dos trabalhos enviados reportam-se à questão saúde-doença em diferentes abordagens.

Estudo sobre o V Congresso de Ciências Sociais e Humanas, em $2011^{52}$, aponta que os 21 Grupos de Trabalho totalizaram 1.482 trabalhos. Em número de trabalhos apresentados, os cinco principais grupos foram: movimentos sociais e educação popular em saúde (156), integralidade, mediações sociais e justiça na demanda por cuidado em saúde (137), humanidade e humanização em saúde (132), análise de narrativa e experiência de saúde, adoecimento e cuidado (130), análise de políticas públicas e de saúde no Brasil (107). Duas tendências são apontadas: "a pulverização de temas ou questões abordadas" e a "prevalência de análises microssociais".

\section{Identidade cognitiva}

Lepenies estabelece que a identidade cognitiva emerge quando é possível identificar claramente as orientações de pesquisa, os paradigmas, os problemas e os instrumentos em um campo específico de conhecimento. Foi com base nessa dimensão que Villas Bôas ${ }^{46}$ realizou extensa pesquisa em 700 livros, do período de 19401964, a fim de analisar a produção científica das ciências sociais no Brasil.

Tanto na identidade histórica como na social, o campo foi cotejado com a produção científica, mas ao tratarmos da identidade cognitiva destacamos, de forma geral, o período que se inicia nos anos 70 .

Nessa década as ciências sociais em saúde marcam de forma clara sua presença no cenário do conhecimento. Isto ocorre em diferentes instituições onde aparecem muitos trabalhos que utilizam teorias, conceitos e métodos sociológicos caminhando para uma produção sistematizada e regular. A produção estende-se por diversas áreas e temáticas, salientando-se os estudos epidemiológicos, as análises sobre as relações saúde e trabalho, prática médica, empresas médicas, produção de medicamentos, assistência médica, prática de saúde ${ }^{53}$. Ilustraremos com uns poucos exemplos. São teses e livros que tratam de assuntos pioneiros na literatura nacional, e que incluem trabalhos de cientistas sociais, médicos e outros profissionais, como o estudo sobre o processo de estigmatização da lepra ${ }^{54}$, escolha da medicina como profissão ${ }^{55}$, hábitos ali- 
mentares ${ }^{56}$, análise crítica da medicina preventi$\mathrm{va}^{57}$, mercado de trabalho médico ${ }^{58}$, emergência da medicina comunitária ${ }^{59}$, enfermagem como profissã $0^{60}$, origens da medicina social brasileira e da psiquiatria ${ }^{61}$, instituições de saúde ${ }^{62}$, o trabalho médico na perspectiva do materialismo histórico ${ }^{63}$, e muitos outros trabalhos.

Sem dúvida, nos anos 70, o social como analisou Donnangelo ${ }^{53}$, referindo-se aos estudos epidemiológicos, mas que estendemos aos demais, "não aparece sob a forma de uma variável adicionada ao elenco de fatores causais da doença, mas como um campo estruturado no interior do qual a doença adquire um específico significado social". As pesquisas realizadas abriam um caminho e demarcavam um campo que nas décadas seguintes seria amplamente desenvolvido.

Assim, um estudo de uma amostra da produção nos anos 90 evidencia o interesse em se "pensar a área" ${ }^{\text {, }}$, reafirmando as amplas possibilidades das análises sociológicas, em diversos temas, mas com poucos trabalhos de caráter epistêmico, em que as questões teóricas estejam presentes de forma detalhada.

Ao longo dos anos o campo foi se estruturando em vertentes teóricas, situando-o no mesmo nível de outros campos de interesse da sociologia, antropologia e ciência política. Nesse sentido, trava-se um debate frente à crise dos modelos das grandes explicações, totalizantes, o que conduz à percepção da necessidade de se trabalhar os micros aspectos sociais, a subjetividade, a questão da construção das identidades coletivas, com a utilização de conceitos que permitissem a mediação entre estrutura e ação social. Também critica-se o caráter restritivo que ocorreu na análise das relações do Estado com as políticas de saúde quando da utilização de uma perspectiva estrutural. Novamente, volta-se a comentar a necessidade de se articular as dimensões macro e micro, associadas ao resgate dos atores coletivos. De outro lado, a doença passa a ser estudada em seus aspectos simbólicos, por meio das próprias narrativas dos sujeitos adoecidos. As trajetórias profissionais irão acrescentar ao campo dos estudos das profissões de saúde, especialmente a médica, uma nova perspectiva, completando os aspectos histórico-sociais que já vinham sendo objeto de investigação, numa vertente de pesquisas qualitativas extremamente originais ${ }^{65}$.

A década de 90 seria um momento de consolidação das pesquisas em ciências sociais, ampliando temáticas, incluindo novas; é também o momento em que há um movimento ascendente de pesquisas fora do campo exclusivo daquelas realizadas no âmbito dos cursos de pós-graduação em saúde coletiva. Predominam temas relacionados à política e instituições de saúde, saúde e sociedade, recursos humanos, planejamento, gestão e avaliação dos serviços de saúde e, logo abaixo os movimentos sociais e saúde, educação e comunicação em saúde, saúde reprodutiva, sexualidade e gênero, teoria e metodologia da pesquisa, sistemas terapêuticos ou alternativos de cura, violência e saúde ${ }^{66}$.

No início dos anos 2000 a diversidade temática continua presente; além dos temas anteriores consolidam-se aqueles voltados para o estudo social da ciência e da técnica, políticas públicas e de saúde, racionalidades e práticas em medicina(s) e saúde, subjetividade e cultura, gênero e saúde. Outros temas como avaliação de políticas de saúde e programas, comunicação e redes de informação, violência e saúde e construção social da saúde e da doença aparecem em menores proporções ${ }^{67}$.

A partir de 2000, diversos trabalhos procuraram mapear a produção científica de diversas maneiras sendo que a análise de artigos aparece em diversos deles. Em uma análise de 411 artigos e 87 resenhas de sete periódicos da área da saúde coletiva, período de 1997-2007, que se autorreferiram como pesquisa qualitativa não foram encontradas marcantes diferenças com as pesquisas já realizadas. Sobre as temáticas, em ordem decrescente pelo volume da produção, os destaques são para políticas e instituições de saúde, saúde e doença, gênero e saúde, violência e saúde, velhice e envelhecimento, recursos humanos, profissões e formação, estudos sociais das ciências e das técnicas e educação e comunicação em saúde ${ }^{68}$.

Nesta cartografia do campo, a pesquisa de Deslandes e Iriart ${ }^{69}$ em 266 artigos publicados em três periódicos (Ciência e Saúde Coletiva, Cadernos de Saúde Pública e Interface), selecionados a partir da leitura de 1.128 resumos como pertencentes ao campo das ciências sociais e humanas encontrou alguns dados que são de interesse para a nossa apresentação. Segundo os autores, "Um total de 124 artigos (46,6\%) define claramente sua filiação a um referencial teórico metodológico", procedentes de uma grande variedade de perspectivas das diversas disciplinas das ciências sociais e humanas. Evidenciam que os estudos utilizam diferentes definições de representações sociais, das abordagens hermenêuticas, construtivistas/construcionistas e das mais diversas correntes teóricas como estudos culturais, interacionistas simbólicos, materialismo histórico, etc. Chamam a atenção que do ponto de 
vista da análise dos dados da pesquisa a quase total predominância da análise de conteúdo.

Importante contribuição para a compreensão do campo na perspectiva do conhecimento foi trazida por Minayo ${ }^{70}$ ao analisar os "caminhos do pensamento" em ciências sociais e humanas sem a preocupação de estabelecer divisões disciplinares. Após o levantamento de 1.757 artigos de sete revistas - Revista de Saúde Pública, Cadernos de Saúde Pública, Ciência \& Saúde Coletiva, Physis, Interface, História, Ciência e Saúde e Saúde e Sociedade - (período de janeiro de 2011 a agosto de 2012), encontrou 545 (33,0\% do total) que são de ciências sociais e humanas stricto sensu ou de saúde coletiva que utilizam o referencial teórico ou metodológico dessas áreas. Ao classificar essa produção constata a existência das seguintes temáticas: status das ciências sociais e humanas em saúde; instituições; interpretação das ações e fenômenos humanos e sociais que afetam a saúde; relações de poder e profissionais; sentidos atribuídos pelos atores à saúde, doença e ao sistema (este é o item que contém maior número de artigos); saúde de grupos específicos. Relevante é a consideração que "As abordagens conceituais e metodológicas são as mais diversas, passando por teorias sociais que privilegiam o papel do ator, os estudos institucionalistas, a historiografia e a história oral, as abordagens econômicas, a fenomenologia, o compreensivismo, a hermenêutica, o referencial marxista, as teorias empiristas, a etnografia, a etnometodologia e, embora em resquício, algumas abordagens funcionalistas".

Toda esta revisão destaca a presença das ciências sociais em saúde como parte integrante do conhecimento, caracterizando-se por uma perspectiva teórica pluralista e por uma diversidade metodológica ampla, com forte referência à pesquisa qualitativa. Já nos anos 80 , Pereira ${ }^{71}$, ao elaborar o primeiro trabalho de análise teórica das teorias subjacentes ao campo da medicina social, apontava que os referenciais da sociologia a partir do funcionalismo estrutural, materialismo histórico e sociologia compreensiva estavam presentes nas pesquisas realizadas. Ao resgatar alguns exemplares produzidos na década de 70 , Pereira desvelava a presença dos grandes teóricos da sociologia no campo das pesquisas em medicina/saúde.

\section{Considerações finais}

À construção da identidade subjaz uma poderosa construção social e ao longo dessa trajetória onde se cruzam biografias, historia e estrutura, para usar uma ideia de Wright Mills ${ }^{72}$, as ciências sociais em saúde, e em particular a sociologia da saúde foram descobrindo passagens, trilhas, caminhos, estradas buscando a sua institucionalização.

De certa forma, repete-se no campo particular, o que havia ocorrido no campo maior da sociologia. Ortiz ${ }^{73}$, ao analisar o campo dos estudos culturais, lembra que "No Brasil, para utilizar um termo caro à intelectualidade latino-americana, a institucionalização das ciências sociais é 'tardia'. A 'escola paulista' de sociologia, personificada na figura de Florestan Fernandes, data dos anos de 1950". Nesse momento, outras disciplinas, como a antropologia, certamente existiam, mas apenas de forma incipiente, desenvolvendose em pontos distantes e desconectados do país e praticadas por um número bastante reduzido de pessoas (a ciência política não existia ainda como especialização).

As ciências sociais se consolidam nos anos 70 e 80, com a emergência de um sistema nacional de pós-graduação, no momento em que se iniciava um processo de formação dos primeiros "grupos" de cientistas sociais em saúde e também da pós-graduação em saúde pública e saúde coletiva. Neste sentido, cumpre destacar que diferente de outros países (Estados Unidos), as ciências sociais em saúde tiveram um estreito vínculo com a área da saúde e não com a área das humanidades no campo universitário. Há, inclusive, em alguns momentos da sua trajetória, especialmente nos anos 80, quando "estabilizaram-se no alcance de institucionalização" ${ }^{2}$ uma visão "instrumental e restrita que tendia a identificá-las pelo exclusivo e limitado recorte da política de saúde". Para Novaes ${ }^{2}$ a visão utilitarista e instrumental previa que o cientista social perderia a sua importância e papel no momento em que a Reforma Sanitária concluísse o seu processo, o que não ocorreu.

Em realidade, a expansão atual, inclusive com a publicação de coletâneas e livros, não analisados neste artigo, conduziu a uma melhor qualificação das pesquisas e a retomada da metodologia sociológica como fundamental para as pesquisas em saúde, com ênfase na pesquisa qualitativa e uma pluralidade teórica, sem as polarizações de décadas anteriores. 
Como mostramos em outros trabalhos e neste artigo, a identidade da Sociologia da Saúde está sendo construída e passada a "fase heróica" enfrentada pelos primeiros cientistas sociais. Assim, compreendemos que há a necessidade de que se formalizem os canais para a formação das novas gerações de cientistas sociais em saú- de, se ampliem e se criem novos meios de divulgação da produção científica e se aprofundem e se institucionalizem as relações, de um lado com as matrizes sociológicas e de outro, com o campo da saúde. O presente estudo é parte do Projeto História da Sociologia da Saúde, Bolsa de Produtividade IA, CNPq.

\section{Referências}

1. Lepenies W, editor. Geschichte der Soziologie: Studien zur kognitiven, sozialen und historischen Identität einer Disziplin. Frankfurt: Suhrkamp; 1981.

2. Novaes MR. Contribuições ao pensamento social em saúde no Brasil [tese]. Campinas (SP): Universidade Estadual de Campinas; 2004.

3. Cândido A. Formação da literatura brasileira. São Paulo: Itatiaia; 1975.

4. Gomes L. O Brasil dos viajantes. [texto da internet]. [acessado 2012 jul 5]. Disponível em: http:// guiadoestudante.abril.com.br/estudar/historia/brasil-viajantes

5. Ferreira LO. José Francisco Xavier Sigaud: um personagem esquecido, uma obra reveladora. Hist Cienc Saude Manguinhos 1998; 5(1):125-126.

6. Ferreira LO. Uma interpretação higienista do Brasil: medicina e pensamento social no Império. XXIII Encontro Anual da ANPOCS, Caxambu, MG, 1999. [site da internet] [acessado 2012 jul 07]. Disponível em: http://www.bvshistoria.coc.fiocruz.br/lildbi/ docsonline/get.php?id=225.

7. Edler FC. De olho no Brasil: a geografia médica e a viagem de Alphonse Rendu. Hist. Cienc. SaudeManguinhos 2001; 8(Supl.):925-943.

8. Lisboa KM. O Brasil dos naturalistas: Spix e Martius. Acervo 2009; 22(1):179-194.

9. Santos Filho L. História geral da medicina. São Paulo: Hucitec, Edusp; 1977.

10. Cabral O. Cultura e folclore. Florianópolis: Imprensa Oficial do Estado de Santa Catarina; 1954.

11. Araújo AM. Medicina rústica. Rio de Janeiro: Editora Nacional; 1959.

12. Carvalho CD. Feiticeiros, burlóes e mistificadores: criminalidade e mudança das práticas populares de saúde em São Paulo - 1950 a 1980. São Paulo: Editora UNESP; 2005.

13. Queiroz MS, Canesqui AM. Contribuições da antropologia à medicina: uma revisão de estudos no Brasil. Rev Saude Publ 1986; 20(2);141-151.

14. Fernandes F. Folclore e mudança social em São Paulo. São Paulo: Anhembi; 1961.
15. Fontenelle LFR. Aimorés: análise antropológica de um programa de saúde. São Paulo: Departamento de Documentação (DASP); 1959.

16. Witter NA. Curar como arte e ofício: contribuições para um debate historiográfico sobre saúde, doença e cura. Tempo 2005; 10(19):13-25.

17. Loyola MA. Médicos e curandeiros. São Paulo: Difel; 1984.

18. Montero P. Da doença à desordem: a magia na umbanda. Rio de Janeiro: Graal; 1985.

19. Oliveira ER. O que é medicina popular? São Paulo: Brasiliense: 1985

20. Nunes ED. Tendências e perspectivas das pesquisas em ciências sociais e saúde na América Latina: uma visão geral. In: Nunes $\mathrm{ED}$, organizador. As ciências sociais e saúde na América Latina: tendências e perspectivas. Brasília: OPAS; 1985. p. 31-71.

21. Vilhena LR. Projeto e missão: o movimento folclórico brasileiro 1947-1964. Rio de Janeiro: Funarte, Fundação Getúlio Vargas; 1997.

22. Paiva CHA. Raimundo Nina Rodrigues: um antropólogo avant la lettre. Hist Cienc Saude Manguinhos 2001; 5(3):761-766.

23. Corrêa M. As ilusões da liberdade: A Escola Nina Rodrigues e a antropologia no Brasil. Bragança Paulista: Editora da Universidade São Francisco; 2000.

24. Maio MC. A medicina de Nina Rodrigues: análise de uma trajetória científica. Cad Saude Publica 1995; 11(2):226-237.

25. Bastide R. Sociologia e psicanálise. São Paulo: Melhoramentos, Editora Universidade de São Paulo; 1974.

26. Bastide R. A psiquiatria social. Arq. serv. assist. psicopatas estado Sao Paulo 1954; 19(1-2):53-143.

27. Bastide R. Sociologia das doenças mentais. Lisboa: Publicações Europa- América; 1968.

28. Nogueira O. Vozes de Campos do Jordão: experiências sociais e psíquicas do tuberculoso pulmonar no Estado de São Paulo. 2a ed. Rio de Janeiro: Fiocruz; 2009. 
29. Mussolini G. Os meios de defesa contra a moléstia e a morte em duas tribos brasileiras: Kaingang de Duque de Caxias e Bororo Oriental [dissertação]. São Paulo: Escola Livre de Sociologia e Política; 1945.

30. Oliveira NS. Estudos de comunidade, ciências sociais e saúde: o ciclo de pesquisas no Vale do São Francisco na década de 1950 [dissertação]. Rio de Janeiro: Fiocruz; 2010.

31. Fernandes F. Um retrato do Brasil. In: Fernandes F. Mudanças sociais no Brasil. $3^{a}$ ed. São Paulo: Difel; 1979.

32. Maio MC, Lima NT. Tradutores, intérpretes ou promotores de mudança? Cientistas sociais, educação sanitária rural e resistências culturais (1940-1960). Soc estado 2009; 24(2):529-561.

33. Lima NT, Maio MC. Ciências sociais e educação sanitária: a perspectiva da Seção de Pesquisa Social do Serviço Especial de Saúde Pública na década de 1950. Hist Cienc Saude Manguinhos 2010; 17(2):511526.

34. Oshiro JH. Educação para a saúde nas instituições de saúde pública [dissertação]. São Paulo: Pontifícia Universidade Católica de São Paulo; 1989.

35. Figueiredo RED. Cuidando da saúde do vizinho: as atividades de antropólogos norte-americanos no Brasil [dissertação]. Campinas: Unicamp; 2004.

36. Renovato RD, Bagnato MHS. Educação Sanitária e o Serviço Especial de Saúde Pública (1942-1960): A doença não conhece fronteiras. Hist. Enf. Rev. Eletr. 2011; 2:105-125.

37. Cardoso JLR. Educando os educadores: ciências sociais e educação sanitária na experiência do SESP (1950-1960) [tese]. Rio de Janeiro: Fiocruz; 2009.

38. Rios JA. A saúde como valor social. Boletim do SESP 1953; 33:2-3.

39. Rios JA. As ciências sociais e saúde pública. Boletim do SESP 1953; 38:2-3.

40. Medina CA. A favela e o demagogo. São Paulo: Livraria Martins; 1964.

41. Wagley C. A educação sanitária no Brasil. Boletim do SESP 1945; 25:5-8.
42. Braga JCS, Paula SG. Saúde e Previdência- estudos de política social. São Paulo: Cebes-Hucitec; 1981.

43. Castro J. Geografia da Fome. Rio de Janeiro: Editora O Cruzeiro; 1946.

44. Freyre G. Sociologia da medicina: breve introdução ao estudo dos seus princípios, dos seus métodos e das suas relações com outras sociologias e com outras ciências. Lisboa: Fundação Calouste Gulbenkian; 1967.

45. Maio MC, Lopes TC. Da escola de Chicago ao nacional desenvolvimentismo: saúde e nação no pensamento de Alberto Guerreiro Ramos (1940 1950). Sociologias 2012; 14(30):290-329.

46. Villas Bôas GK. A vocação das ciências sociais. Um estudo de sua produção em livro 1945-1966. Rio de Janeiro: Fundação Biblioteca Nacional; 2007.

47. Villas Bôas GK. A tradição renovada. In: Bomeny $\mathrm{H}$, Birman P, organizadoras. As assim chamadas ciências sociais. Rio de Janeiro: Relume-Dumará; 1991. p. 21-41.

48. Nascimento JL. Uma (con) figuração: cientistas sociais, antropólogos, sociólogos e cientistas sociais [tese]. Campinas: Unicamp; 2011.

49. Barros NF. Os cientistas sociais no Sistema Único de Saúde. Campinas; 2013; 158 p. (mimeo).

50. Almeida LEDF. Contribuição para o estudo da comunidade científica da saúde coletiva: os grupos de pesquisa [tese]. Unicamp; 2011.

51. Gomes MHA, Goldenberg P. Interfaces e interlocuções: os congressos de ciências sociais em saúde. Cien Saude Colet 2003; 8(1):261-264.

52. Trad LAB. Temas e enfoques contemporâneos nas Ciências Sociais e Humanas no Brasil: expressões e tendências refletidas no $\mathrm{V}$ congresso da área. Cad Saude Publ 2012; 28(12):2373-2379.

53. Donnangelo MCF. A pesquisa na área da saúde coletiva no Brasil: a década de 70. In: Associação Brasileira de Pós-graduação em Saúde Coletiva (Abrasco). Ensino da Saúde Pública, Medicina Preventiva e Social no Brasil. Rio de Janeiro: Abrasco; 1983. p. 17-35. 
54. Gandra Junior D. Lepra: uma introdução ao estudo do fenômeno social da estigmatização [tese]. Belo Horizonte: Faculdade de Filosofia e Ciências Humanas; 1970.

55. Nunes ED. A medicina como profissão: contribuição ao estudo da escolha ocupacional entre os estudantes de medicina [tese]. Campinas: Universidade Estadual de Campinas; 1976.

56. Canesqui AM. Comida de pobre, comida de rico [tese]. Campinas: Universidade Estadual de Campinas; 1976.

57. Arouca ASS. O dilema preventivista: contribuição para a compreensão e crítica da medicina preventiva [tese]. Campinas; Universidade Estadual de Campinas; 1975.

58. Donnangelo MCF. Medicina e sociedade. O médico e seu mercado de trabalho. São Paulo: Pioneira; 1975.

59. Donnangelo MC, Pereira L. Saúde e sociedade. São Paulo: Duas Cidades; 1976.

60. Ferreira-Santos CA. A enfermagem como profissão. São Paulo: Livraria Pioneira, Edusp; 1973.

61. Machado R, Loureiro A, Luz R, Muricy K. Danação da norma: Medicina Social e constituição da Psiquiatria no Brasil. Rio de Janeiro: Graal; 1978.

62. Luz MT. As instituições médicas no Brasil: instituições e estratégias de hegemonia. Rio de Janeiro: Edições Graal; 1979.

63. Mendes-Gonçalves RB. Medicina e historia: raízes sociais do trabalho médico. São Paulo [dissertação]. São Paulo: Universidade de São Paulo; 1979.

64. Nunes ED. As ciências sociais e a saúde: o pensamento recente de alguns pesquisadores. In: Canesqui AM, organizador. Dilemas e desafios das ciências sociais na saúde coletiva. São Paulo, Rio de Janeiro: Hucitec, Abrasco; 1995. p. 53-61.
65. Nunes ED. A trajetória das ciências sociais em saúde na América Latina: revisão da produção científica. Rev Saude Pub 2006; 40(número especial):64-72.

66. Canesqui AM. Ciências Sociais e saúde: três décadas de ensino e pesquisa no Brasil. Cien Saude Colet 1998; 3(1):131-168.

67. Nunes ED. Sociologia da saúde: história e temas. In: Campos GWS, Bonfim JRA, Minayo MCS, Akerman M, Drumond Jr M, Carvalho YM, organizadores. Tratado de Saúde Coletiva. 2a ed. São Paulo: Hucitec; 2012. p. 283-315.

68. Canesqui AM. Temas e abordagens das ciências sociais e humanas em saúde na produção acadêmica de 1997 a 2007. Cien Saude Colet 2010; 15(4):19551966.

69. Deslandes SF, Iriart JAB. Usos teórico-metodológicos das pesquisas na área de Ciências Sociais e Humanas em Saúde. Cad Saude Publica 2012; 28(12): 2380-2386.

70. Minayo MCS. A produção de conhecimentos na interface entre as ciências sociais e humanas e a saúde coletiva. Saúde soc 2013; 22(1):21-31.

71. Pereira JCM. A explicação sociológica na medicina social. São Paulo: Editora UNESP; 2006.

72. Mills CW. A imaginação sociológica. Rio de Janeiro: Zahar Editores; 1965.

73. Ortiz R. Estudos culturais. Tempo Social 2004; 16(1):119-127.

Artigo apresentado em 10/05/2013

Aprovado em 30/05/2013

Versão final apresentada em 02/06/2013 